\title{
Nanostructure Multilayer Materials for Capacitor Energy Storage for EH Vehicles
}

T. W. Barbee Jr.

G. W. Johnson

February 1995

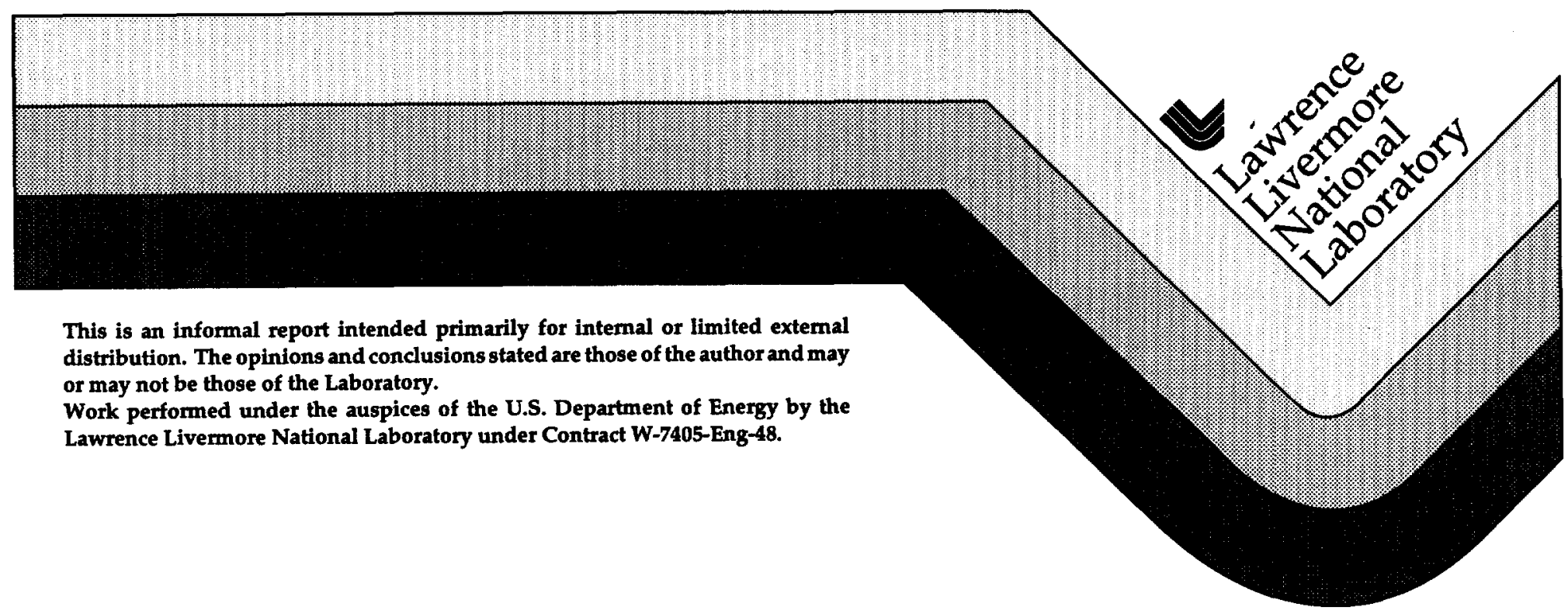




\section{DISCLAIMER}

This document was prepared as an account of work sponsored by an agency of the United States Government. Neither the United States Government nor the University of California nor any of their employees, makes any warranty, express or implied, or assumes any legal liability or responsibility for the accuracy, completeness, or usefulness of any information, apparatus, product, or process disclosed, or represents that its use would not infringe privately owned rights. Reference herein to any specific commercial product, process, or service by trade name, trademark, manufacturer, or otherwise, does not necessarily constitute or imply its endorsement, recommendation, or favoring by the United States Government or the University of California. The views and opinions of authors expressed herein do not necessarily state or reflect those of the United States Government or the University of California, and shall not be used for advertising or product endorsement purposes.

This report has been reproduced directly from the best available copy.

Available to DOE and DOE contractors from the Office of Scientific and Technical Information

P.O. Box 62, Oak Ridge, TN 37831

Prices available from (615) 576-8401, FTS 626-8401

Available to the public from the

National Technical Information Service

U.S. Department of Commerce

5285 Port Royal Rd.,

Springfield, VA 22161 


\section{Introduction}

Acceleration and regenerative breaking for electric and hybrid vehicles require high power capacitors to complement energy sources. Large, flat nanostructure multilayer capacitors (NMCs) can provide load balancing capacitance in EHVs of the future. Additional uses include snubber capacitors for power electronics such as motor drives, energy discharge capacitors for lasers, and numerous industrial and military electronics applications [1]. In the present work, we demonstrate the effectiveness of LLNL's multilayer materials technology by fabricating NMC test films with high energy and power density.

Nanostructure multilayer materials are widely known in the materials community for scientific study and physics applications. They are characterized by a near-atomic scale and thus, uniquely large interfacial area to volume ratios. Parallel-plate conductor-dielectric structures fabricated using multilayer technology give us the ability to engineer high performance capacitors. We can optimize properties by materials selection, design of the synthesis process, and materials processing. This is a great advantage when compared to conventional capacitor fabrication techniques using bulk materials.

Two primary figures of merit for capacitors are of interest to the EHV community: power density and energy density. Very high power density is guaranteed in the NMC design because the parallel-plate conductors are of substantial size for low resistance, and the chosen metaloxide dielectric materials have low loss. High energy density can be obtained by increasing the dielectric constant, $k$, or by increasing the breakdown voltage, $V_{b}$. Breakdown voltage is especially important because energy density goes the square of $V_{b}$. In multilayer synthesis we can manipulate $k$ by alternately depositing thin layers of two or more dielectric materials with different dielectric constants. This also allows us to intermix materials for an optimum tradeoff between $k$ and $V_{b}$.

In general, interface rather than bulk phenomena dominate the breakdown process when high electric fields are applied [2]. By depositing a very thin layer of a particular material between the conductor and dielectric, we can alter the interfacial work function to reduce carrier injection thus increasing breakdown voltage. This technique may also be used to control electrochemical effects and electromigration at the conductor-dielectric interface. The atomically-smooth interfaces achieved in this synthesis process, which are maintained over macroscopic distances, reduce localized electric field stresses, further enhancing $V_{b}$. Additionally, multilayer dielectrics allow flexible application of materials to mitigate edge effects-the intensification of electric field lines at discontinuities - that otherwise severely reduce the working voltage of a capacitor. These are the keys to improving energy density through the use of nanostructure multilayer materials. 


\section{Test Capacitor Fabrication Methods}

The sputter deposition apparatus applied in this program is a facility resource in the Vapor Phase Synthesis Laboratory of the Chemistry and Materials Science Department at LLNL originally funded by Defense Programs. It has been substantially modified using funds provided as part of a Cooperative Research and Development Agreement (CRADA) program between UNITED TECHNOLOGIES CORPORATION acting through its Pratt \& Whitney, Government Engines \& Space Propulsion Division and Lawrence Livermore National Laboratory. The CRADA title is DEVELOPMENT AND IMPLEMENTATION OF ADVANCED MATERIALS FOR AIRCRAFT ENGINE APPLICATIONS: DEVELOPMENT AND IMPLEMENTATION OF NANO-STRUCTURE LAMINATES. This CRADA is largely directed to the development of refractory oxide Thermal Barrier Coating structures for application in air breathing gas turbine engines. As a result the technology for high rate deposition of refractory oxide materials was developed at LLNL under this program and is the subject of a Patent Disclosure and is being developed for a Patent Application. This research and development sputter deposition system has the capability to sequentially deposit a nanostructure refractory oxide material with individual component layers having thicknesses of 25 to $5000 \AA$ and macroscopic thicknesses of up to $50 \mu \mathrm{m}$ in an 8 hour deposition run.

In general terms this deposition process is an extension of earlier work [3,4] of one of the principals on reactive sputter deposition of refractory oxides. In this process a metal target is used as the sputtered material source and is maintained in an inert sputter gas atmosphere. Metal atoms are sputtered at rates substantially higher than possible by normal reactive sputtering or by sputtering from a refractory oxide target. These are deposited onto a substrate maintained in an oxygen partial pressure sufficient to oxidize the metal atoms impinging onto the deposition surface enabling very high refractory oxide deposition rates and control of the stoichiometry of the depositing material. It has been demonstrated that large area pinhole free films can be fabricated using this technology making it appropriate for nanostructure capacitor development.

The substrates used in this work were single crystal (100) orientation device quality silicon having a characteristic surface roughness of 4 to $6 \AA$ rms. This substrate material was selected as it is readily available, cleaning procedures are well established and it is inexpensive as a research and development substrate. A base electrical contact was deposited over the full surface of the silicon substrates that consisted of a copper-chrome carbide multilayer structure. This material is very strong, has a smoothness replicating that of the substrate and is very stable with temperature. The dielectric structure under study was then deposited over the $\mathrm{Cu} / \mathrm{Cr}_{3} \mathrm{C}_{2}$ multilayer leaving an electrical contact aperture. The contact array shown in the following figure was then deposited through a laser machined contact mask using $\mathrm{Cu} / \mathrm{Cr}_{3} \mathrm{C}_{2}$ multilayers or high purity $(99.999 \%)$ aluminum. 


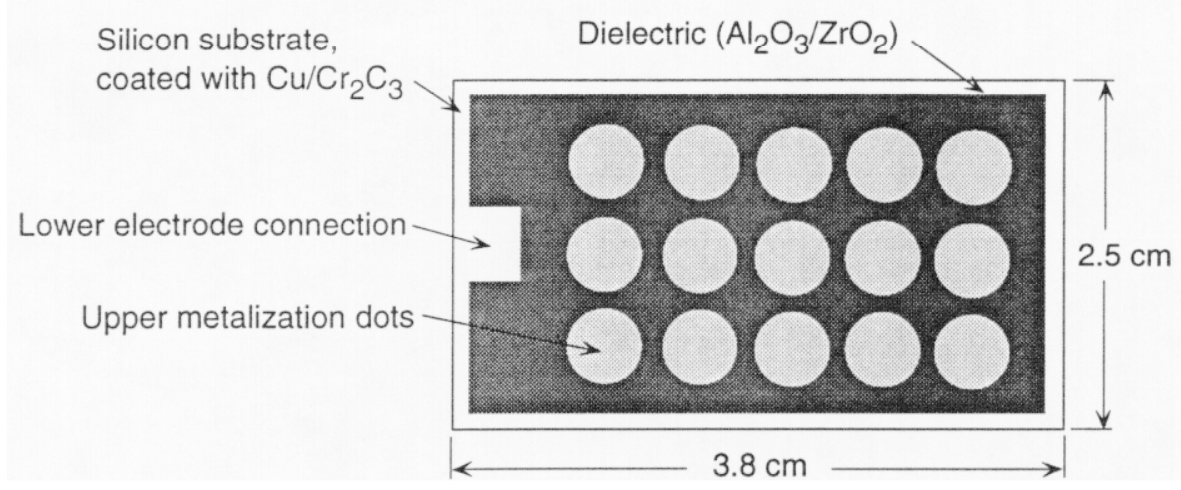

A dielectric test film. The silicon substrate is coated with metal, over which a multilayer dielectric is applied. An array of metal dots are deposited to form the upper contacts.

\section{Dielectric Materials Selection}

The dielectric materials applied in this nanostructure capacitor development program are zirconium dioxide $\left(\mathrm{ZrO}_{2}\right)$ and aluminum oxide $\left(\mathrm{Al}_{2} \mathrm{O}_{3}\right)$. These were selected as base line developmental materials based on the existing synthesis data available from the CRADA program and the differences in their dielectric constants. Literature values reported for the dielectric constants of $\mathrm{ZrO}_{2}$ and $\mathrm{Al}_{2} \mathrm{O}_{3}$ differ by over a factor of two and are 21 and 8.8 respectively. This allows investigation of the effects of compositional variations introduced by variation of the relative component layer thicknesses in the nanostructure material on the nanostructure dielectric constant and breakdown characteristics. Higher dielectric constant materials were considered but were not pursued as the development of a sufficient synthesis data base could not be supported with the available funding.

\section{Measurements}

Deposited films and capacitor structures were subjected to compositional and structural characterization and electrical testing using facilities available in the LLNL Chemistry and Materials Science Programs.

\section{Materials Analysis Methods}

Dielectric thickness was measured with a Sloan Dektak with an uncertainty of $\pm 0.01 \mu \mathrm{m}$, implying an accuracy of $\pm 0.3 \%$ on a $3 \mu \mathrm{m}$ sample. The physical structural quality of the nanostructure dielectric materials were characterized using grazing incidence $\mathrm{X}$-ray diffraction for determination of the multilayer period and cross-section transmission electron microscopy 
(TEM) for direct observation of interfacial characteristics and layer uniformity. The crystal structure of the individual layers was determined both by selected area diffraction (SAD) in the electron microscope and high angle X-ray powder diffractometry (XRD). Composition was determined using Rutherford Back Scattering Spectroscopy (RBS) on specially prepared samples using an amorphous carbon substrate. Use of the amorphous carbon substrate eliminated substrate interference with the oxygen, zirconium and aluminum back scattering signals substantially enhancing the accuracy of these measurements. Vicker's Hardness was also measured using a standard laboratory micro-indenter apparatus on nanostructure films at least $5 \mu \mathrm{m}$ thick.

\section{Electrical Test Methods}

Fundamental electrical characteristics of the test films were measured by conventional means. Quantities measured were:

- Capacitance vs. frequency

- DC breakdown voltage

- Dielectric resistivity

\section{Capacitance}

Capacitance at each dot was measured with a Hewlett-Packard 4194A Impedance Gain/Phase Analyzer with a model 41941A impedance probe. The probe is a four-terminal device usable to $100 \mathrm{MHz}$. Routine calibration and probe zero/offset adjustments were performed prior to each measurement session. The analyzer displays impedance magnitude and phase versus frequency and computes equivalent circuit parameters using a selected model. The model for these capacitors is a series RLC network, where $R$ is the equivalent series resistance (ESR) and $L$ is the equivalent series inductance (ESL). Because the capacitor dots are very small, the ESR and ESL measurements were often dominated by parasitic effects.

\section{Breakdown voltage}

Breakdown voltage was determined by applying a variable $\mathrm{DC}$ high voltage as shown below. The specimen was placed in a Petri dish filled with 3M Fluorinert FC-72 to prevent coronainduced damage or breakdown. A series resistor limits the applied power. Polarity was switched during some tests, but no significant difference in results was observed. Voltage was increased manually in either 10 or $100 \mathrm{~V}$ steps, or by smooth, continuous adjustment. The latter technique results in a higher apparent breakdown voltage. The operator observes the current during the test and notes the presence of current spikes that indicate self-healing breakdowns, and large step increases in current indicating device failure. A record of current vs. voltage is kept during the test. Just prior to breakdown, the measured current is required to 
calculate the actual capacitor voltage:

$$
V_{\mathrm{c}}=V_{\mathrm{s}}-I R
$$

where $V_{c}$ is the capacitor voltage, $V_{s}$ is the source voltage, $I$ is the measured current, and $R$ is the series resistance, $1.0 \mathrm{M} \Omega$.

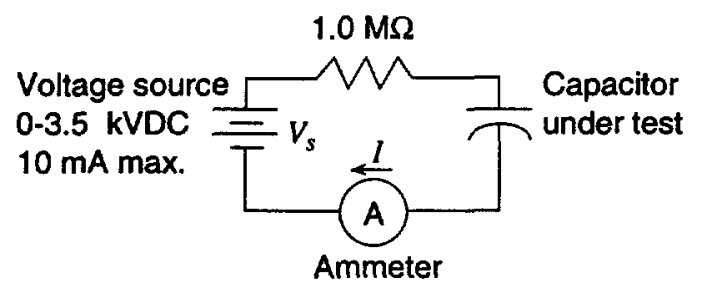

DC breakdown voltage test circuit. The resistor limits current to a safe value.

\section{Dielectric resistivity}

Dielectric resistivity was evaluated with the circuit below. A Kiethley 485 picoammeter was used. The minimum detectable current was $100 \mathrm{fA}$. Alternatively, a commercial high-resistance ohmmeter could be used. Resistivity is calculated from:

$$
\rho=\frac{V_{s} a}{l d}
$$

where $a$ is the dielectric area and $d$ is the dielectric thickness.

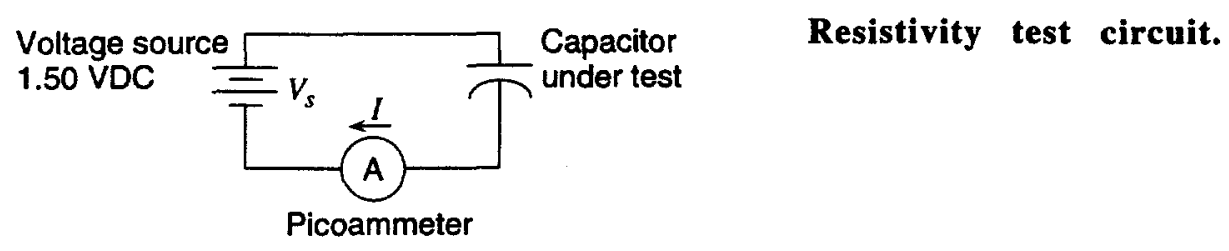




\section{Experimental Results}

A total of 14 capacitor test films were fabricated and tested. There were more than 46 other synthesis runs focused on CRADA objectives for purposes of system checkout, source characterization, deposition rate calibration, for producing materials analysis samples and to fabricate samples for evaluation by Pratt \& Whitney, our industrial CRADA partner.

\section{Macroscopic Structure}

A dielectric thickness profile is shown in the following figure. The central half of the sample film is flat to within about $3 \%$. Tapering is due to the shielding effects of the oxygen shroud and substrate holder located above the substrate.
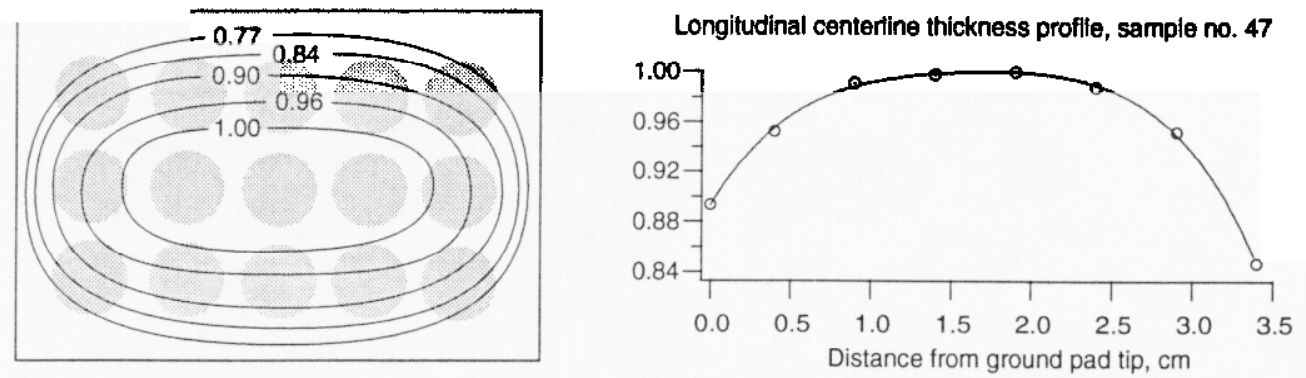

Left, contour plot showing relative dielectric thickness over the deposition area for a typical sample. Right, the centerline thickness profile. Note that the profile is flat to within $3 \%$ over half the length of the sample.

\section{Microscopic Structure and Composition}

The quality of these nanostructure laminate refractory oxide films is shown in the figure on the next page, a set of cross-section TEM images of $\mathrm{ZrO}_{2} / \mathrm{Al}_{2} \mathrm{O}_{3}$ structures having equal layer thicknesses and periods of $10,20,100,200$ and $400 \mathrm{~nm}$. The uniformity of the layering as well as the chemical abruptness of the interfaces in these structures is clearly demonstrated. The $\mathrm{Al}_{2} \mathrm{O}_{3}$ layers were observed to be amorphous (SAD TEM and XRD) in all cases independent of thickness or layering. Their composition was determined to be $\mathrm{Al}_{2} \mathrm{O}_{3 \pm 0.03}$ by $\mathrm{RBS}$ analysis as described above. The crystal structure of the $\mathrm{ZrO}_{2}$ layers was observed to vary with their thickness independent of layering. At layer thicknesses less than approximately $50 \mathrm{~nm}$ the $\mathrm{ZrO}_{2}$ was fully amorphous. Crystallization of the growing layer was observed in layers 50,100 and $200 \mathrm{~nm}$ thick and is observed in the figure above for the $400 \mathrm{~nm}$ period structure. The 
Development and Implementation of

\section{Nano-Laminate Structures}

- Cross- Section Transmission Electron Micrographs of $\mathrm{ZrO}_{2}-\mathrm{Al}_{2} \mathrm{O}_{3}$ Nano-Laminate (NL) TBC Structures

- NL Periods: $10 \mathrm{~nm} ; 20 \mathrm{~nm} ; 100 \mathrm{~nm} ; 200 \mathrm{~nm} ; 400 \mathrm{~nm}$

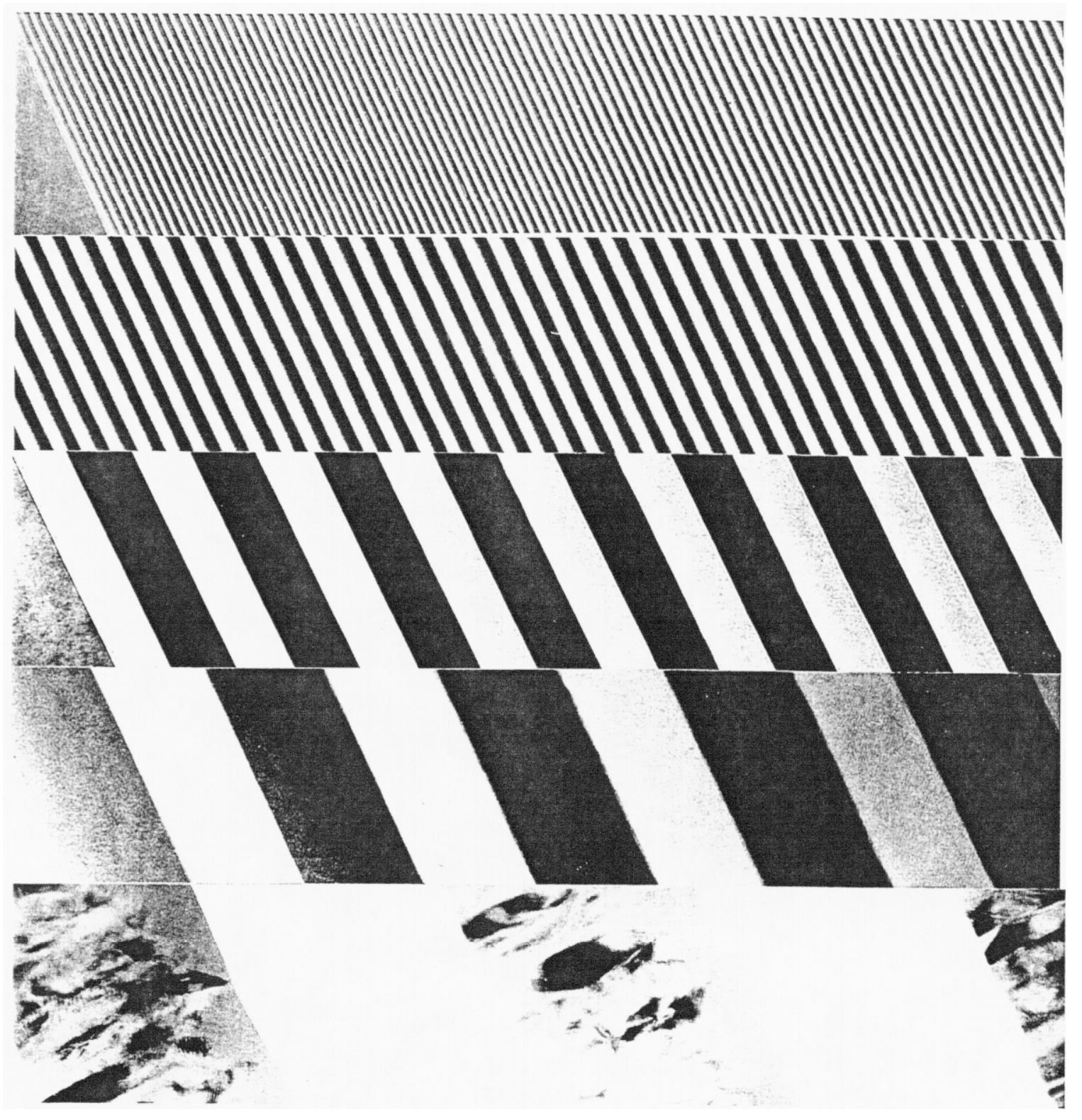


crystal form of this material was monoclinic and appeared to be random orientation. No experiments designed to explore this observation have been undertaken at this time. RBS analysis of the zirconium oxide material showed it to have the composition $\mathrm{ZrO}_{2 \pm 0.02}$. It is important to note that the RBS data showed that a slight cross contamination of $\mathrm{Al}$ in $\mathrm{ZrO}_{2}$ and $\mathrm{Zr}$ in $\mathrm{Al}_{2} \mathrm{O}_{3}$ occurred during synthesis. This cross contamination was of the same order as the uncertainty in the oxygen concentrations but clearly observable in the RBS spectra.

\section{Electrical Performance}

Electrical characteristics of each test film are tabulated in Appendix A. Following is a discussion of the results and the associated models.

\section{Capacitance and dielectric constant}

Capacitance was measured for each functional dot. Values ranged from 0.3 to $1.0 \mathrm{nF}$ for all samples, the variation being due to changes in dielectric thickness and composition. The value for thickness used in our calculations is that of one of the center dots, which are in the most uniform deposition region. From capacitance, we calculate the effective dielectric constant, or relative permitivity, for the multilayer composite material:

$$
k=\frac{C d}{\varepsilon_{o} a}
$$

where $C$ is capacitance, $d$ is dielectric thickness, $a$ is the dot area, and $\varepsilon_{0}$ is the permitivity of free space, $8.854 \times 10^{-12} \mathrm{~F} / \mathrm{m}$. The following figure shows the variation of dielectric constant with composition. Published values of $k$ for bulk $\mathrm{Al}_{2} \mathrm{O}_{3}$ and $\mathrm{ZrO}_{2}$ are 8.8 and 21 , respectively, and this data falls within that range.

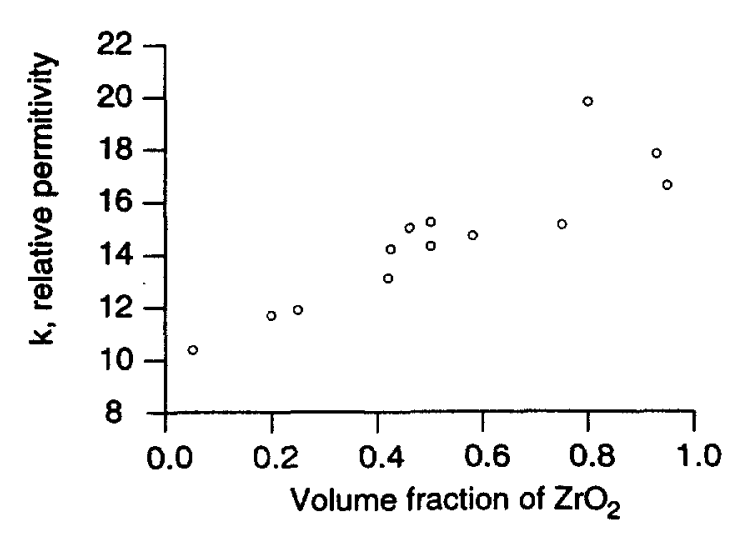

Dielectric constant is an approximately linear function of composition for twocomponent multilayer dielectrics.

The functional relationship between effective dielectric constant and volume fraction in multilayer materials has not been discussed in the literature, to the best of our knowledge. It is 
approximately linear over the range of interest.

\section{Dielectric resistivity}

Dielectric resistivity for a total of 27 dots on three of the best sample films was measured. The graph below shows the distribution of values for each film. For sample 55, four dots showed leakage currents below the threshold of the picoammeter, $100 \mathrm{fA}$, and are reported as $10^{16}$ $\Omega \mathrm{cm}$. For comparison, some commercial $1 \mathrm{nF}$ ceramic and mylar capacitors were tested in the same fixture and no leakage was detectable.

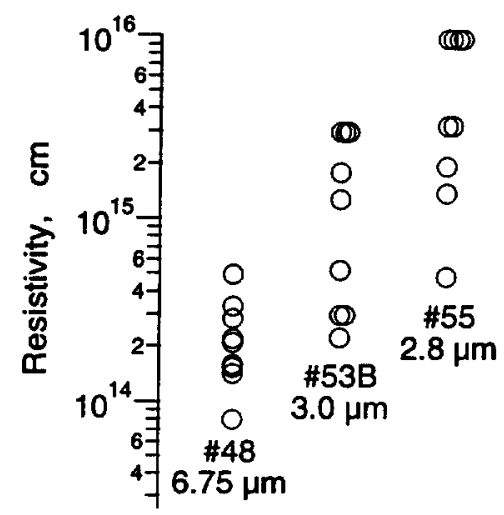

\section{Dielectric resistivity for three test films.}

\section{Breakdown voltage}

A wide variation in breakdown voltage was observed among test films and among individual dots. We attribute much of this variation to the presence of particulate contamination. The following graph shows the relationship between breakdown field intensity and dot yield, a measure of the percentage of non-shorted dots on a given test film. Films that were relatively free of contamination generally showed a higher yield and a higher breakdown strength. This data clearly indicates a need for careful substrate preparation, clean-room practices, and careful design of the deposition system to minimize contamination.

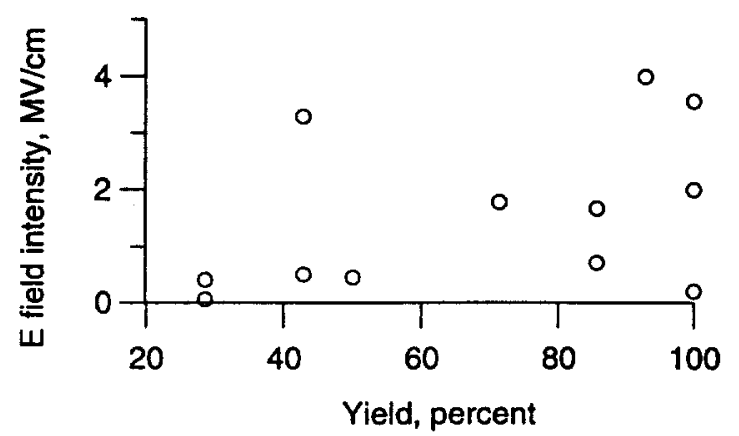

Electric field intensity at breakdown vs. the percentage of non-shorted dots on the test films.

While ramping the DC voltage during breakdown testing, all samples showed momentary current spikes, sometimes accompanied by an audible click and a small flash of blue light 
indicative of an arc. These events were generally followed by a reduction in steady-state leakage current. This is typical self-healing behavior where a defect in the dielectric causes localized electric field intensification, followed by breakdown and vaporization of material in the area of the defect. After the defect is cleared, the potential can be increased until another weak point fails in a similar manner. Eventually, a catastrophic failure occurs, permanently shorting the film.

Maximum DC breakdown voltage was $1200 \mathrm{~V}$ for a $3.0 \mu \mathrm{m}$ dielectric that consisted of $2.5 \mu \mathrm{m}$ of a multilayer $\left(500 \AA \mathrm{ZrO}_{2} / 500 \AA \mathrm{Al}_{2} \mathrm{O}_{3}\right.$ ) followed by a $0.5 \mu \mathrm{m}$ layer of $\mathrm{Al}_{2} \mathrm{O}_{3}$. The electric field at that potential is $4.0 \mathrm{MV} / \mathrm{cm}$. Similar results $(3.57 \mathrm{MV} / \mathrm{cm})$ were obtained with a $2.8 \mu \mathrm{m}$ multilayer consisting of $100 \AA \mathrm{ZrO}_{2} / 400 \AA \mathrm{Al}_{2} \mathrm{O}_{3}$.

\section{Energy storage}

Knowing the breakdown voltage, capacitance, and dielectric volume, we calculate peak energy density from

$$
W_{d}=\frac{\text { Energy }}{\text { Volume }}=\frac{0.5 C V_{b}^{2}}{a d}
$$

Maximum energy densities, considering only the dielectric material, were 11.0 and $6.9 \mathrm{~J} / \mathrm{cm}^{3}$. A practical multilayer capacitor would have up to $10 \%$ of its volume occupied by conductor material, reducing theses figures to 9.9 and $6.2 \mathrm{~J} / \mathrm{cm}^{3}$. Additional reductions in working energy density are required for safety factor derating.

Specific energy can be calculated by dividing energy density by the density of the dielectric. Density of these multilayer materials varies with composition and can be approximated by the expression

$$
\gamma=\phi_{z} \gamma_{z}+\left(1-\phi_{z}\right) \gamma_{a}
$$

where $\gamma_{z}$ is the density of zirconia $\left(5.8 \mathrm{~g} / \mathrm{cm}^{3}\right), \gamma_{a}$ is the density of alumina $\left(4.0 \mathrm{~g} / \mathrm{cm}^{3}\right)$, and $\phi_{z}$ is the volume fraction of zirconia. Maximum specific energies were 2.3 and $1.6 \mathrm{~J} / \mathrm{g}(0.64$ and $0.45 \mathrm{Whr} / \mathrm{kg}$ ) achieved with the same specimens that produced the highest energy densities.

It is impractical to accurately measure specific power for such small devices because the measurement is dominated by the parasitic resistance and inductance of the test fixture. An estimate can be obtained from the measured effective series resistance computed by the network analyzer during the measurement of capacitance. For our highest-energy sample, 53B, ESR was $0.4 \pm 0.2 \Omega$. Peak power at the $1200 \mathrm{~V}$ breakdown voltage into a matched, non-reactive load $\left(R_{L}=E S R\right)$ is calculated from 


$$
P=\frac{V_{b}^{2}}{4 E S R}
$$

which yields $0.9 \mathrm{MW}$. Dividing by the mass of the dielectric $(0.25 \mathrm{mg})$ produces a peak specific power of $3.5 \times 10^{9} \mathrm{~W} / \mathrm{g}$. This very high value is typical of small, high-quality capacitors used for electronic applications. We are confident that NMC technology can achieve similar specific power at all scales.

Additionally, a subjective indication of high specific power was observed: When catastrophic breakdown occurred on the high-energy samples, the instantaneous $1 \mathrm{~mJ}$ energy discharge resulted in a visible hole blown in the metal dot, and shock waves would reverberate in the surrounding dielectric fluid. In some samples, the acoustic shock was enough to delaminate the multilayer from the silicon substrate.

\section{Summary and Conclusions}

A series of nanostructure multilayer capacitor test films have been fabricated and characterized. Very high energy and power densities have been demonstrated. Table 1 summarizes the specifications of one of the samples fabricated here.

Table 1. Specification Summary-Test Film Sample No. 53B

\begin{tabular}{|l|l|}
\hline Dielectric & Zirconia/alumina nanostructure multilayer \\
\hline Conductors & CuCrC multilayer base, Al dots \\
\hline Dielectric thickness & $3.0 \mu \mathrm{m}$ \\
\hline Dielectric constant & 15.5 \\
\hline Dielectric density & $4.75 \mathrm{~g} / \mathrm{cm}^{3}$ \\
\hline Dielectric volume & $5.34 \times 10^{-5} \mathrm{~cm}^{3}$ \\
\hline Dielectric resistivity & $10^{15} \mathrm{ohm}-\mathrm{cm}$ \\
\hline Capacitance & $813 \mathrm{pF}$ \\
\hline Breakdown voltage & $1200 \mathrm{~V}$ \\
\hline Breakdown field & $4.0 \mathrm{MV} / \mathrm{cm}$ \\
\hline ESR & $0.4 \Omega$ \\
\hline Energy density & $11 \mathrm{~J} / \mathrm{cm}^{3}(3.1 \mathrm{Whr} / \mathrm{)})$ \\
\hline Specific energy & $2.3 \mathrm{~J} / \mathrm{g}(0.64 \mathrm{Whr} / \mathrm{kg})$ \\
\hline Specific power & $3.5 \mathrm{X} 10^{9} \mathrm{~W} / \mathrm{g}$ \\
\hline
\end{tabular}


Critical elements in the synthesis process have been investigated and quantified:

- Stoichiometry as a function of oxygen partial pressure $\left(\mathrm{O}_{2}\right.$ molecule incidence rate onto the substrate)and source power (metal atom deposition rate)is controllable - CRADA

- $\mathrm{Crystal}$ structure can be controlled to some degree for the $\mathrm{ZrO}_{2}$ by limiting layer thickness and by layering different materials in adjacent layers - CRADA \& EE/DOE

- Dielectric constant is a simple function of the individual dielectrics constants of the constituent materials. EE/DOE

Other important facts established in this project:

- Dielectric constant of very thin layers of metal oxides may differ from published values for bulk materials- Not Surprising

- NMC devices show self-healing voltage breakdown capacity - EE/DOE

- Particulate contamination control is vital for successful dielectric synthesis - EE/DOE.

NMC development will continue with DOE funding in FY95 and beyond. Other dielectrics and combinations of dielectrics are expected to provide higher $k$. Dielectric-metal interfaces will be modified through the deposition of very thin layers of other materials, which should increase $V_{b}$. Enhancements to existing synthesis techniques will be investigated, such as the introduction of ozone, that improve stoichiometry control and permit us to fabricate larger devices. Complex capacitor structures will be fabricated using automated masking apparatus.

Results from this modest initial phase show that NMC technology is competitive with other high-energy density capacitor technologies now under development. Our continuing efforts will produce practical devices suitable for large-scale manufacturing and use in a wide variety of applications. 


\section{References}

1. T. W. Barbee, Jr., G. W. Johnson, and D. W. O'Brien, High Energy Density Capacitors Using Nano-structure Multilayer Technology, LLNL whitepaper (1993).

2. M. W. Hillen, M.M. Heyns, S. K. Haywood, R. F. De Keersmaecker, Influence of Charge Buildup on Breakdown and Wear-Out of Thin $\mathrm{SiO}_{2}$ Layers on Silicon. Proc. Ist International Conference on Conduction and Breakdown in Solid Dielectrics, NY: IEEE (1983).

3. T. W. Barbee, Jr., D. L. Keith, L. Nagel and W. A. Tiller, J. Electro. Chem. Soc. 131, 434 (1984)

4. B. T. Khuri-Yakub, J. G. Smits and T. W. Barbee, Jr., J. Appl. Phys. 52, 4772 (1981)

\section{Acknowledgments}

The authors would like to thank the following people for their valued contribution to this work: Mr. Barry Olsen and Mr. Eric Fought-Deposition system fabrication and operation; Mr. Mark Wall-Transmission Electron Microscopy; Dr. Andrew Wagner-Rutherford Backscattering Analysis; Dr. Tim Weihs-X-Ray Diffraction Analysis; Mr. Dennis O’Brien-Program liaison. 


\begin{tabular}{|c|c|c|c|c|c|c|c|c|c|c|c|c|c|c|c|c|c|c|c|c|c|c|}
\hline Sample ID & Analyzed & Suhstrate & Base metal & Top metal & $\begin{array}{l}\text { Delectric } \\
\text { description }\end{array}$ & $\begin{array}{l}\text { Dielecterlc } \\
\text { Thickness }\end{array}$ & Toxal & $\begin{array}{l}\text { Towil } \\
\text { A12O3 } \\
\end{array}$ & $\begin{array}{c}\text { Vol Frac } \\
\text { Zro2 }\end{array}$ & c & $\mathbf{k}$ & ESR & $\begin{array}{l}\text { Delectick } \\
\text { leakinge }\end{array}$ & $\begin{array}{l}\text { Dictectinc } \\
\text { nesisdivity }\end{array}$ & $\mathbf{b}$ & w & w & $\begin{array}{l}\text { Delectric } \\
\text { Volune }\end{array}$ & wd & $\mathrm{wm}_{\mathrm{m}}$ & \begin{tabular}{c|c} 
Good \\
dost
\end{tabular} & Noter \\
\hline & dete & & & & & $\mu \mathrm{m}$ & $\mathbf{k}$ & $k \dot{k}$ & & $\mathbf{F}$ & & $\mathrm{m} n$ & $\Omega$ & $\Omega \mathrm{cm}$ & $\mathbf{v}$ & MVKam & $\mathrm{I}$ & $\boldsymbol{c}$ & עec & $\begin{array}{ll}/ 8 & 1 \\
\end{array}$ & $14 \max$ & \\
\hline $94-2 \mathrm{~A}-35 \mathrm{~B}$ & $11 / 15 / 94$ & $\begin{array}{l}\text { St, } 1.0^{n} \times \\
1.5^{n}\end{array}$ & Cucre & $\operatorname{CuCNC}$ & $\begin{array}{c}100 \hat{Z} \mathrm{ZOO} 2,100 \AA \\
\mathrm{A} 203\end{array}$ & 1.7 & 3.35 & 5.35 & 0.50 & $1.14 E-09$ & 12.24 & & & & 220 & 1.29 & $2.75 E-05$ & $3.03 \mathrm{E}-05$ & 0.91 & 0.19 & 41 & 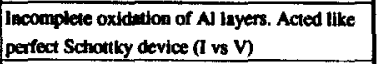 \\
\hline $94-2 \Lambda-46$ & $12 / 294$ & $\begin{array}{c}51,1.0^{n} x \\
1.5^{n}\end{array}$ & $\mathrm{CuCrC}$ & $\mathrm{cr}$ & $\begin{array}{c}450 \mathrm{Z} 2 \mathrm{rO2}, 450 \mathrm{X} \\
\mathrm{A1203}\end{array}$ & 4.48 & 22.4 & 22.4 & 0,0 & 5.74E-10 & 16.31 & 41080 & & & 200 & 0.45 & $15 E-05$ & 7.98E-05 & 0.14 & 0.03 & 7 & Very low breakdown voluge. \\
\hline 94-2A-47 & $12 / 5,594$ & $\begin{array}{c}1,1.0^{n} \times \\
1.5^{*} \\
\end{array}$ & Cucre & $\begin{array}{c}\mathrm{Cu} \\
1.0 \pm 0.1 \mu \\
\end{array}$ & $\begin{array}{c}450 \mathrm{~A} 2 \mathrm{ZrO2.450 \lambda} \\
\mathrm{A} 1203 \\
\end{array}$ & 2.195 & 11 & 11 & 0.50 & $1.04 E-09$ & 14.50 & 200 & & & 10 & 0.05 & $3.21 E-08$ & $3.91 \mathrm{E}-05$ & 0.00 & 0.00 & 4 & Very low breakdowa vollage. \\
\hline 94.2A 48 & $12 / 599$ & $\begin{array}{c}51,1.0^{*} \times \\
1.5^{*} \\
\end{array}$ & $\mathrm{CuCrC}$ & $\begin{array}{c}\mathrm{Cu}, \\
1.0 \pm 0.1 \mu\end{array}$ & $\begin{array}{c}\begin{array}{c}450 \lambda \mathrm{ZrO2}, 450 \mathrm{~A} \\
\mathrm{A203}\end{array} \\
\end{array}$ & 6.75 & 31 & 36.5 & 0.46 & $3.68 E-10$ & 15.75 & 151078 & $1.0 E+10$ & $6 \mathrm{E}+12$ & 1200 & 1.78 & $2.65 \mathrm{E}-04$ & $1.20 \mathrm{E}-04$ & 2.20 & 0.46 & 10 & $\begin{array}{l}0.3 \mu \text { of ZnO2 (by scoddent). Seff-healing ares } \\
\text { during Vb lesting }\end{array}$ \\
\hline 94-2A-19 & & $\begin{array}{l}\text { Si, } 1.0^{m} \mathrm{x} \\
1.5^{m}\end{array}$ & $\operatorname{cucrc}$ & $a$ & $\begin{array}{c}.24 \mathrm{AN} 203.24 \\
\mathrm{ZrO2} .24 \mathrm{AN} 2 \mathrm{OB} \\
5.4 \mathrm{ZrO}\end{array}$ & 5.98 & 36 & 4 & 0.93 & $4.77 \mathrm{E}-10$ & 18.09 & 150 & $5.5 E+08$ & $1.6 \mathrm{E}+11$ & 1200 & 2.01 & $3.436-04$ & $1.07 \mathrm{E}-04$ & 3.22 & 0.57 & 6 & $\begin{array}{l}\text { Thickneas mesured on complementary side. } \\
\text { Dielectrde lifed from metal a aner final (Mg) anc }\end{array}$ \\
\hline 94-2A-50A & 127794 & $\begin{array}{l}\text { SN, } 1.0^{n} \times \\
1.5^{n}\end{array}$ & CuCre & cu & $\begin{array}{c}24 \mathrm{~N} 203.24 \\
2 \mathrm{rO}, 3.4 \mu \mathrm{N} 203 \\
\end{array}$ & 4 & 2 & 38 & 0.05 & $4.39 \mathrm{E}-10$ & 11.14 & 40 & $E+09$ & $E+11$ & 200 & 0.50 & 8E-06 & $7.12 E-05$ & 0.12 & 0.03 & 14 & \\
\hline 94-2A-50B & 127194 & $\begin{array}{c}S, 1.0^{n} \mathrm{x} \\
1.5^{*} \\
\end{array}$ & $\mathrm{CrC}$ & $\mathrm{Cu}$ & $\begin{array}{c}.24 \mathrm{Zr} 02,24 \\
\mathrm{~N} 203,3.4 \mu \mathrm{ZOO}\end{array}$ & 4 & 38 & 2 & 0.95 & $7.14 \mathrm{E}-10$ & 18.11 & 150 & & & $\mathbf{0}$ & 0.20 & $2.28 E-06$ & 7.12E-05 & 0.03 & 0.01 & 4 & Thickness nominal; not measured. \\
\hline $94-2 A-5 i A$ & 122894 & $\begin{array}{l}\text { Si, } 1.0^{-1} \times \\
1.5^{n} \\
\end{array}$ & Cucre & $\omega$ & 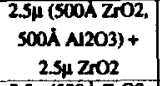 & 5 & 37.5 & 12.5 & 0.75 & 5.08E-10 & 16.11 & 85 & & & 10 & 0.02 & $254 E-08$ & $8.91 E-05$ & 0.00 & 0.00 & 12 & $\begin{array}{l}\text { Thickness nominal; not meassured. Vb was }<10 \\
\text { v. }\end{array}$ \\
\hline 94-2A-S1B & $12 / 894$ & $\begin{array}{l}\text { Si, } 1.0^{n} \times \\
1.5 \\
\end{array}$ & $\mathrm{CuCrC}$ & w & $\begin{array}{c}2.54(500 \mathrm{ZZO} 2 \\
500 \mathrm{~A} \mathrm{A2O} 3)+ \\
2.54 \mathrm{Al2O3}\end{array}$ & 5 & 12.5 & 375 & 0.25 & $3.97 \mathrm{E}-10$ & 12.58 & $\boldsymbol{x}$ & $20 E+09$ & $7.1 E+11$ & 200 & 0.40 & 7.93E-08 & $8.91 E-05$ & 0.09 & 0.02 & 14 & Thickness nomindi; not messured. \\
\hline 94-2A-52A & $12 / 1294$ & $\begin{array}{c}\$ 1,1.0^{n} \times \\
1.5^{*} \\
\end{array}$ & $C$ & $\boldsymbol{N}$ & 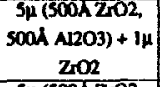 & 6 & 35 & 25 & 0.58 & $4.27 E-10$ & 16.25 & 450 & $1.06+10$ & $3.0 E+12$ & 1000 & 1.67 & $2.146-04$ & $1.07 \mathrm{E}-04$ & 200 & 0.40 & 13 & Thlatiness nominal; not mensured \\
\hline 94-2A-52B & $12 / 1294$ & $\begin{array}{c}\text { Su. } 1.0^{-} \times \\
1.5^{*} \\
\end{array}$ & CuCrC & 소 & 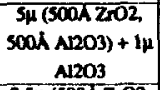 & 6 & 25 & 33 & 0.42 & $3.76 \mathrm{E}-10$ & 14.29 & 480 & $1.2 E+10$ & $3.6 \mathrm{E}+12$ & 1200 & 2.00 & $2.700-04$ & $1.07 \mathrm{E}-04$ & 2.53 & 0.53 & 12 & Thickness nominal; nol measurod. \\
\hline 94-2A-53B & $12 / 12 / 94$ & $\begin{array}{l}\text { SU. } 1.0^{n} \mathrm{x} \\
1.5^{*}\end{array}$ & cuck & A & 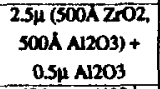 & 3 & 125 & 17.3 & 0.42 & $8.13 \mathrm{E}-10$ & 13.47 & 400 & $6.0 E+09$ & $3.6 \mathrm{E}+12$ & 1200 & 4.00 & 5.85E-04 & $5.34 \mathrm{E}-05$ & 10.96 & 231 & 14 & $-1,1-1$ \\
\hline $94-2 \mathrm{~A}-54$ & $12 / 13 / 94$ & $\begin{array}{l}3,1.0^{4} \times \\
1.5^{n}\end{array}$ & $\mathrm{CuCrC}$ & $\mathbf{N}$ & $\begin{array}{c}60 \text { layou }(400 \mathrm{~A} \\
\mathrm{ZTO2} 100 \mathrm{~A} \\
\text { A2203) }\end{array}$ & 28 & 24 & 6 & 0.80 & $1.17 \mathrm{E}-09$ & $20 \%$ & 350 & $2.0 E+09$ & $1.3 \mathrm{E}+12$ & 200 & 0.71 & $2.33 E-05$ & 499E-0S & 0.47 & 0.09 & 9 & $\begin{array}{l}\text { Thictress measured on complementiry side. } \\
\text { Subatrme had been used in a prior run but } \\
\text { probubly had no coating. }\end{array}$ \\
\hline & 1215994 & $\begin{array}{l}\text { Si, } 1.0^{n} \times \\
1.5^{n}\end{array}$ & cucre & $\mathbf{N}$ & $\begin{array}{c}60 \text { liyen }(100 \mathrm{~K} \\
\mathrm{Z} \times 2 \mathrm{2} 400 \mathrm{~A} \\
\mathrm{~A} 2 \mathrm{2003})\end{array}$ & 2.8 & 6 & 24 & 0.20 & $0.91 \mathrm{E}-10$ & 12.27 & 600 & $2.8 E+09$ & 1.7E+12 & 1000 & 357 & IOE & $4.998-05$ & 6.93 & 1.59 & & $\begin{array}{l}\text { Complement of rin 54. Investigating K vs } \\
\text { composition. High-gride substrate. }\end{array}$ \\
\hline
\end{tabular}




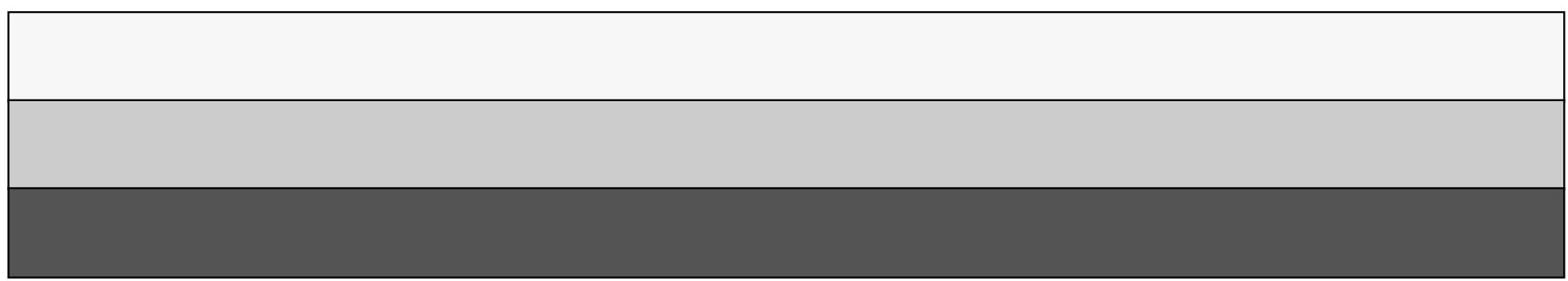

